\title{
Radiological nodule behavior: A critical parameter in the surgical management of pediatric pulmonary metastases
}

\author{
Emre Divarc1 ${ }^{1}$, Serkan Arslan ${ }^{1}$, Zafer Dökümcü ${ }^{1}$, Mehmet Kantar², Bengü Demirağ ${ }^{3}$, \\ Haldun Öniz ${ }^{4}$, Yeşim Ertan ${ }^{5}$, Hüdaver Alper ${ }^{6}$, Ata Erdener ${ }^{1}$, Coşkun Özcan ${ }^{1}$ \\ Departments of ${ }^{1}$ Pediatric Surgery, ${ }^{2}$ Pediatric Oncology, ${ }^{5}$ Pathology and ${ }^{6}$ Pediatric Radiology, Ege University Faculty of \\ Medicine, İzmir, ${ }^{3}$ Department of Pediatric Oncology, Dr Behcet Uz Child Disease and Surgery Training and Research Hospital, \\ ${ }^{4}$ Department of Pediatric Oncology, Tepecik Training and Research Hospital, İzmir, Turkey.E-mail: emre.divarci@ege.edu.tr \\ Received: 27th April 2017, Accepted: 27th November 2017
}

SUMMARY: Divarcı E, Arslan S, Dökümcü Z, Kantar M, Demirağ B, Öniz H, Ertan Y, Alper H, Erdener A, Özcan C. Radiological nodule behavior: A critical parameter in the surgical management of pediatric pulmonary metastases. Turk J Pediatr 2018; 60: 372-379.

Radiological nodule behavior (RNB) means the course of nodule appearance on consecutive CT scans. In this study, we aimed to discuss the effects of RNB on prognosis of patients with pulmonary metastasis. Retrospective analysis of patients who underwent pulmonary metastasectomy (PM) between 20052015 was performed. RNBs were grouped as stable, enlarging or new rising nodules. The effects of RNBs were analyzed on recurrence, 1- and 3-year event free survival (EFS) and mortality.

Twenty-seven patients (18 male) underwent PM with a median age of 15 years (3-18 years). The diagnoses were listed as osteosarcoma (13), Wilms' tumor (7), Ewing's sarcoma (3), synovial sarcoma (2), rabdomyosarcoma (1) and mixed germ cell tumor of testis (1). RNBs were new rising in 15 patients $(55 \%)$, enlarging in seven patients $(26 \%)$ and stable in five patients (19\%). Vital tumor metastasis was detected in all of the patients with enlarging nodules (100\%); in 10 of the 15 patients with new rising nodules $(66 \%)$ and none of the patients with stable nodules. None of the patients with stable nodules developed recurrence or died after PM $(p<0.05)$. In patients with enlarging nodules, metastases recurred and they died in the postoperative period. These findings were similar in different types of tumors. RNB could be used as a critical parameter in deciding surgical management strategies of pulmonary metastases. Stabile nodules should be observed by close follow-up with serial CT scans without surgery. All of the suspected new rising nodules should undergo surgical sampling to avoid unnecessary chemotherapy. Nodule progression under chemotherapy is a poor prognostic criteria for overall survival.

Key words: children, osteosarcoma, pulmonary metastasectomy, pulmonary metastasis, pulmonary nodule.

Pulmonary metastases could be seen frequently in some of the childhood tumors such as osteosarcoma, Ewing's sarcoma or Wilms' tumor. Treatment of these disorders consists of a multidisciplinary approach such as surgery, chemotherapy, and/or radiotherapy (RT). The significant positive effects of pulmonary metastasectomy (PM) had been demonstrated on long- term survival in adults and children in several studies. ${ }^{1-5}$ Sometimes, pulmonary metastasectomy could be more significant than the course of the primary tumor at the prognosis.

There is no unique management strategy for various types of pediatric pulmonary metastases. Different treatment options can

This study was presented at the 34th National Congress of Turkish Association of Pediatric Surgeons (TAPS), Girne, Cyprus, 2016, and was awarded with "the Prof. Dr. Nebil Büyükpamukçu Oncology Scientific Research Prize". The study was also presented in the 17th European Pediatric Surgeons' Association (EUPSA) Congress in Milano 2016, as poster presentation. 
be necessary according to the type and stage of the tumor. Several factors such as size, localization and number of the metastatic nodules were investigated in previous studies to demonstrate their effects on prognosis and survival. ${ }^{3-7}$ The characteristics of radiological nodule appearance, such as size or calcification on computerized tomography (CT) scan was investigated to distinguish the nature of the the nodule as malignant or benign. ${ }^{8}$

Radiological nodule behavior (RNB) means the course of the nodule appearance on consecutive CT scans before and after chemotherapy. The nodules could disappear, enlarge or begin to appear firstly after initial medical treatment. In this study, we aimed to discuss the effects of radiological nodule behavior in prognosis in patients who underwent PM.

\section{Material and Methods}

Retrospective analysis of patients who underwent pulmonary metastasectomy (PM) in our clinic between 2005 and 2015 was performed. A pulmonary nodule was defined as demonstration of a noticeable nodule on helical CT scan. The diameter of the nodule could be diverse according to the radiological appearance as calcific or non-calcific. The effects of parameters included number, size and localization of the nodules, extent of resection, timing of metastasis, viability of the tumor tissue and radiological nodule behavior (RNB) were analyzed on outcomes, i.e. recurrence, 1-year and 3-year event free survival (EFS) and mortality. The types of nodule behavior on radiological studies were classified as:

Stable nodule: diagnosed at the beginning of the disease and did not shrink or enlarge after chemotherapy.

Enlarging nodule: diagnosed at initial admission, and enlarged after chemotherapy.

New rising nodule: identified for the first time in the post-chemotherapy period or late recurrence of the nodules which disappeared in the early post-chemotherapy period.

Nodules which disappeared after chemotherapy did not require surgery. So, we did not enroll these patients into this study. The effects of nodule behavior and the other parameters such as number, size, localization of the nodules and the type of surgical resection on prognosis were analysed to determine the effects of these parameters on prognosis.

The criteria for PM were considered as follows: total resection or control of primary tumor site; sufficient pulmonary capacity after resection; no extrapulmonary metastasis; feasibility of complete resection verified by preoperative work-up and no superior treatment modality rather than surgical excision. ${ }^{2}$ The surgical approach as thoracoscopy or thoracotomy was decided according to the visualization and resectability of the nodules and the aim of the procedure as diagnostic or curative.

Management strategies were decided according to the primary diagnosis and the aim of the procedure as curative or diagnostic. Pulmonary metastasectomy was performed for achieving cure and treatment in patients with the diagnosis of osteosarcoma, Wilms' tumor, synovial sarcoma and mixed germ cell tumor of the testis. However, in diagnosis of Ewing's sarcoma or rabdomyosarcoma, procedures were applied to reveal the suspected radiological conditions for pulmonary metastasis. Thus, oncologists could decide the requirement for additional chemotherapy or radiotherapy. Only localized and small pulmonary metastasis in Ewing's sarcoma underwent metastasectomy to achieve cure. Some of these patients with huge pulmonary metastasis underwent mestastasectomy to reduce the tumor size to achieve effective external radiotherapy.

All types of the malignancies, regardless of presence of lung metastasis, underwent chemotherapy as an initial treatment. The decision of surgery was determined after chemotherapy. Patients were investigated by helical CT scan again after chemotherapy in order to evaluate the final status of lung metastasis. If no nodule was detected on CT scan, patients were followed without surgery. Control CT scans were obtained in every 3-6 months periods in the first year after chemotherapy. Surgical excision was performed in patients with nodule behaviors such as: stabile nodules with suspected radiological features for pulmonary metastasis, new rising nodules or enlarging nodules. Detected nodules on CT scan were evaluated for possibility of surgical resection. Chemotherapy/radiotherapy was administered in non- resectable metastatic nodules which could not provide the criterias 
Table I. Clinical Characteristics of Patients with Pulmonary Metastases.

Clinical Characteristics

Median age

Primary diagnosis

Surgical approach

Number of nodules

Nodule size

Nodule localization

\section{Results}

15 years (3-18 years)

Osteosarcoma, $\mathrm{n}=13(48 \%)$

Wilms' tumor, $\mathrm{n}=7$ (26\%)

Ewing's sarcoma, $\mathrm{n}=3(11 \%)$

Synovial sarcoma, $\mathrm{n}=2(7 \%)$

Rabdomyosarcoma, $\mathrm{n}=1$ (4\%)

Mixed germ cell tumor of testis, $n=1 \quad(4 \%)$

Thoracotomy: 21 patients $(77 \%)$

Thoracoscopy: 6 patients $(23 \%)$

Median number of nodules: 2 (range,1-21)

$\geq 4$ nodules: 10 patients $(37 \%)$

Median nodule size: $12 \mathrm{~mm}$ (range, 2-100 mm)

$>10 \mathrm{~mm}: 14$ patients $(51 \%)$

Unilateral: 22 patients $(81 \%)$

Bilateral: 5 patients $(19 \%)$

\section{for PM.}

The research was reviewed and approved by an institutional review board; participation involved informed consent.

The statistical analysis was performed by SPSS for Windows 20.0. Clinical data were converted to crosstabs and underwent Pearson Chi-square and Fisher's exact test analysis. We considered $\mathrm{p}$ values lower than 0.05 to be statistically significant.

\section{Results}

Twenty-seven patients (18M, 9F) underwent 29 surgical procedures with a median age of 15 years (range: 3-18 years). The median follow-up period in the overall group was $31 \pm 33.6$ months (range: 13-145 months). Clinical characteristics and surgical procedures are summurazid in Table I and II, respectively.

Recurrence was seen in nine patients (41\%), and reoperation was performed in two of them. Adjuvant chemotherapy was administered to 14 patients after surgery. Radiotherapy was applied in 10 of these patients after surgery (37\%).

Metastatic nodules were detected during initial diagnosis of the primary tumor in 12 patients $(45 \%)$. In the other patients, pulmonary metastasis was identified in a median period of 18 months after primary diagnosis (range, 796 months). Pulmonary nodules were grouped according to the radiological nodule behavior as new rising nodules in the 15 patients (55\%), enlarging nodules in seven patients $(26 \%)$ and stable nodules in five patients (19\%) (Table III).

Tumor viability was checked in different types of nodule behaviors. Vital tumor metastasis at pathological examination was detected in all of the patients with enlarging nodules (100\%). Although in five of the 15 patients with new rising nodules vital tumor tissue could not be demonstrated at histopathological examination (33\%). Pathological diagnoses in these patients were necrotising tumor tissue (2 patients), calcific granulation tissue (2 patients) or organised pneumonia (1 patient). Vital tumor

Table II. The Characteristics of Surgical Procedures.

Type of surgical excision

Intraoperative nodule findings

The extend of surgical excision
Wedge resection, $\mathrm{n}=13(48 \%)$

Nodulectomy, $\mathrm{n}=7 \quad(26 \%)$

Lobectomy, $n=4$ (15\%)

Segmentectomy, $\mathrm{n}=3$ (11\%)

Visible: $\mathrm{n}=24(88 \%)$

Palpable: $\mathrm{n}=22(81 \%)$

Complete surgical excision: $n=22(81 \%)$ 
Table III. The Pathological Examination of Nodules According to the Radiological Nodule Behavior.

\begin{tabular}{lccc}
\hline Radiological nodule behavior & Vital tumor metastasis & $\begin{array}{c}\text { Necrotizing } \\
\text { tumor tissue }\end{array}$ & $\begin{array}{c}\text { Benign } \\
\text { etiologies }\end{array}$ \\
\hline New rising nodules $(n=15)$ & $10(66 \%)$ & $2(13 \%)$ & $3(21 \%)$ \\
Enlarging nodules $(n=7)$ & $7(100 \%)$ & - & - \\
Stable nodules $(n=5)$ & - & $4(80 \%)$ & $1(20 \%)$ \\
\hline
\end{tabular}

metastasis was identified in 10 of 15 patients with new rising nodules $(66 \%)$. All of the patients with stable nodules had necrotising tumor tissue or calcific granulation tissue and did not necessiate additional treatment.

The effects of radiological nodule behavior on recurrence, 1- and 3-year EFS and mortality in all of the patients regardless of different diagnoses were presented in Table IV. All types of nodule behaviors had not had a significant effect on 1-year EFS. Stable nodules had significant lower rates of recurrence and mortality and a significant positive effect on 3-year EFS statistically. In patients with enlarging pulmonary metastatic nodules, metastases recurred and all of them died in the postoperative period $(100 \%)$. There was not a positive effect on overall survival in enlarging nodules. In patients with new rising nodules, surgical excision did not effect recurrence, 1-year EFS, 3-year EFS or mortality significantly. Most of them died in the first year of PM. Two of these seven patients died after three years of surgical excision. Consequently, PM only had positive effect on lengthening the life span in limited number of patients with enlarged nodules.

The effects of radiological nodule behaviors were analyzed individually according to primary type of the tumor in Table V. The results were almost similar in comparison with the entire group who had different tumor types. All of the patients with enlarging nodules who had osteosarcoma or Ewing's sarcoma died after PM. Similarly, none of the patients with stable nodules who had osteosarcoma, Wilms' tumor or mixed germ cell tumor of the testis had vital tumor metastasis. Also, none of them recurred or died after PM.

The effects of the other parameters (such as number, size and localization of the nodules, extend of resection, timing of metastasis, viability of the tumor tissue) on 1- and 3-year EFS, recurrence and mortality in the overall group were analyzed (Table VI). 1-year EFS could be evaluated in 21 of 27 patients and determined as $81 \%$ in this group. All of the parameters which were stated at methods had no statistical effect on 1-year EFS. 3-year EFS could be assesed in 17 of 27 patients and detected as $58 \%$. Nodule recurrence was seen more frequently in nodules which consisted vital tumor histopathology $(\mathrm{p}=0.052)$. Mortality was seen in eleven of all patients (33\%).

Complications were seen in six patients: pneumothorax (3 patients), atelectasis (2 patients) and pericardial effusion (1 patient). Pneumothorax was treated with tube thoracostomy. Other complications were treated conservatively.

Table IV. The Effects of Radiological Nodule Behavior on Recurrence, 1-year EFS, 3-year EFS and Mortality.

\begin{tabular}{lcccc}
\hline Radiological nodule behavior & Recurrence & $\begin{array}{c}\text { 1-year EFS } \\
(\mathrm{n}=21)\end{array}$ & $\begin{array}{c}\text { 3-year EFS } \\
(\mathrm{n}=17)\end{array}$ & Mortality \\
\hline New rising nodules $(\mathrm{n}=15)$ & $3 / 10(30 \%)$ & $6 / 8(75 \%)$ & $2 / 6(33 \%)$ & $4 / 10(40 \%)$ \\
& $(\mathrm{p}=0.521)$ & $(\mathrm{p}=0.648)$ & $(\mathrm{p}=0.152)$ & $(\mathrm{p}=0.831)$ \\
Enlarging nodules $(\mathrm{n}=7)$ & $6 / 7(85 \%)$ & $3 / 5(60 \%)$ & $2 / 5(40 \%)$ & $5 / 7(71 \%)$ \\
& $(\mathrm{p}=0.002)$ & $(\mathrm{p}=0.197)$ & $(\mathrm{p}=0.377)$ & $(\mathrm{p}=0.021)$ \\
Stable nodules $(\mathrm{n}=5)$ & $0 / 7(0 \%)$ & $7 / 7(100 \%)$ & $5 / 5(100 \%)$ & $0 / 7(0 \%)$ \\
& $(\mathrm{p}=0.015)$ & $(\mathrm{p}=0.101)$ & $(\mathrm{p}=0.017)$ & $(\mathrm{p}=0.015)$ \\
\hline
\end{tabular}

EFS: Event free survival

Each group was compared with the remaining patients of the overall group. 


\section{Discussion}

The literature with large patient numbers about pulmonary metastasectomy usually consists of adult series. ${ }^{1,2,9,10}$ However, the variety of diagnoses in children may be different from adult studies. The prognoses, indications and treatment strategies could also vary according to the type and stage of the tumor. Surgical metastasectomy could be required in various types of the tumors like osteosarcoma, Wilms' tumor, Ewing's sarcoma or rabdomyosarcoma. Pulmonary metastases may occasionally effect the morbidity and mortality rather than the course of the primary tumor.

There is no unique management strategy for all types of pediatric malignancies for pulmonary metastasis. The management strategy for pulmonary metastasis must be indivualized according to the type of the primary tumor. ${ }^{11}$ Also, the aim of the treatment may be different in various type of tumors. ${ }^{12-14}$ Pulmonary metastasectomy (PM) could be performed to complement the whole treatment in osteosarcoma or Wilms tumor. It should be the mainstay of the treatment in localized relapsed tumors. However, Ewing's sarcoma or rabdomyosarcoma are usually diffuse disorders, and surgery is indicated for confirmation of the metastasis in these tumor types. Sometimes, surgical metastasectomy would be necessary to reduce the tumor volume before radiotherapy. In this study, we aimed to investigate the effects of different radiological nodule behaviors on prognosis of patients underwent pulmonary metastasectomy. Thus, we wanted to get critical messages to structure our surgical management strategy. Several prognostic criteria were determined in previous studies as number, localization and size of the nodules. In our study, most of the parameters like number, size and localization of the nodule, complete nodule resection, adjuvant chemotherapy/ radiotherapy or timing of metastasis had no effect on 1 and 3-year EFS, recurrence or mortality. Only few parameters such as nodule behavior as stable or enlargement at nodule size and live tumor metastasis had been shown as positive or negative significant factors. The stability of nodule size had a significant positive effect on 3- year EFS. Tumor recurrence and mortality were seen more frequently in patients with enlarging nodules and live tumor tissue at histopathological examination. The rates of recurrence and mortality were significantly lower in patients with stable nodules. The effects of radiological nodule behaviors (RNBs) were independent from the the type of the primary type of the tumor. These findings were similar in different types of tumors such as osteosarcoma or Ewing's sarcoma. So, we thought that RNBs could be used as a useful

Table V. The Effects of Radiological Nodule Behavior According to Tumor Types.

\begin{tabular}{llll}
\hline Tumor types & Live tumor metastasis & Recurrence & Mortality \\
\hline Osteosarcoma $(\mathrm{n}=13)$ & $8(61 \%)$ & $5(38 \%)$ & $6(46 \%)$ \\
New rising nodules $(\mathrm{n}=5)$ & $3(60 \%)$ & $1(20 \%)$ & $1(20 \%)$ \\
Enlarging nodules $(\mathrm{n}=5)$ & $5(100 \%)$ & $4(80 \%)$ & $5(100 \%)$ \\
Stable nodules $(\mathrm{n}=3)$ & $0(0 \%)$ & $0(0 \%)$ & $0(0 \%)$ \\
Wilms' tumor $(\mathrm{n}=7)$ & $5(71 \%)$ & $20(28 \%)$ & $20(28 \%)$ \\
New rising nodules $(\mathrm{n}=6)$ & $5(83 \%)$ & $2(33 \%)$ & $0(33 \%)$ \\
Stable nodule $(\mathrm{n}=1)$ & $0(0 \%)$ & $0(0 \%)$ & $0(0 \%)$ \\
Ewing's sarcoma $(\mathrm{n}=3)$ & $2(66 \%)$ & $2(66 \%)$ & $2(66 \%)$ \\
Enlarging nodules $(\mathrm{n}=2)$ & $2(100 \%)$ & $2(100 \%)$ & $0(0 \%)$ \\
New rising nodules $(\mathrm{n}=1)$ & $0(0 \%)$ & $0(0 \%)$ & $0(0 \%)$ \\
Synovial sarcoma $(\mathrm{n}=2)$ & $2(100 \%)$ & $0(0 \%)$ & $0(0 \%)$ \\
New rising nodules $(\mathrm{n}=2)$ & & & \\
Rabdomyosarcoma $(\mathrm{n}=1)$ & $0(0 \%)$ & $0(0 \%)$ & $0(0 \%)$ \\
New rising nodules $(\mathrm{n}=1)$ & $0(0 \%)$ & $0(0 \%)$ & \\
Mixed germ cell tumor of testis $(\mathrm{n}=1)$ & & & \\
Stable nodule $(\mathrm{n}=1)$ & & & \\
\hline
\end{tabular}


Table VI. The Effects of Other Parameters on Recurrence, 1-year EFS, 3-year EFS and Mortality.

\begin{tabular}{|c|c|c|c|c|}
\hline & Recurrence & 1-year EFS & 3-year EFS & Mortality \\
\hline $\begin{array}{l}\text { Number of nodules } \\
\geq 4 \text { nodules }(n=10) \\
<4 \text { nodules }(n=14)\end{array}$ & $\begin{array}{l}4 / 10(40 \%) \\
5 / 14(36 \%) \\
(p=0.831)\end{array}$ & $\begin{array}{l}7 / 8(87.5 \%) \\
9 / 12(75 \%) \\
(p=0.494)\end{array}$ & $\begin{array}{l}3 / 6(50 \%) \\
6 / 10(60 \%) \\
(p=0.696)\end{array}$ & $\begin{array}{l}4 / 10(40 \%) \\
5 / 14(36 \%) \\
(\mathrm{p}=0.831)\end{array}$ \\
\hline $\begin{array}{l}\text { Size of nodules } \\
\geq 1 \mathrm{~cm}(\mathrm{n}=14) \\
<1 \mathrm{~cm}(\mathrm{n}=13)\end{array}$ & $\begin{array}{l}4 / 14(28.6 \%) \\
5 / 13(38.5 \%) \\
(p=0.695)\end{array}$ & $\begin{array}{l}7 / 11(63.6 \%) \\
10 / 10(100 \%) \\
(p=0.090)\end{array}$ & $\begin{array}{l}4 / 9(44.4 \%) \\
6 / 8(75 \%) \\
(p=0.335)\end{array}$ & $\begin{array}{l}6 / 14(43 \%) \\
3 / 13(23 \%) \\
(p=0.420)\end{array}$ \\
\hline $\begin{array}{l}\text { Localization } \\
\text { Unilateral }(n=20) \\
\text { Bilateral }(n=4)\end{array}$ & $\begin{array}{l}8 / 20(40 \%) \\
1 / 4(25 \%) \\
(p=0.572)\end{array}$ & $\begin{array}{l}12 / 16(75 \%) \\
4 / 4(100 \%) \\
(p=0.264)\end{array}$ & $\begin{array}{l}5 / 12(42 \%) \\
4 / 4(100 \%) \\
(p=0.088)\end{array}$ & $\begin{array}{l}8 / 20(40 \%) \\
1 / 4(25 \%) \\
(\mathrm{p}=0.572)\end{array}$ \\
\hline $\begin{array}{l}\text { Extend of resection } \\
\text { Complete }(\mathrm{n}=19) \\
\text { Incomplete }(\mathrm{n}=5)\end{array}$ & $\begin{array}{l}7 / 19(37 \%) \\
2 / 5(40 \%) \\
(p=0.897)\end{array}$ & $\begin{array}{l}12 / 16(75 \%) \\
4 / 4(100 \%) \\
(p=0.264)\end{array}$ & $\begin{array}{l}7 / 14(50 \%) \\
2 / 2(100 \%) \\
(p=0.182)\end{array}$ & $\begin{array}{l}8 / 19(42 \%) \\
1 / 5(20 \%) \\
(p=0.364)\end{array}$ \\
\hline Adjuvant chemotherapy $(n=14)$ & $\begin{array}{l}7 / 14(50 \%) \\
(p=0.134)\end{array}$ & $\begin{array}{l}9 / 11(82 \%) \\
(p=0.822)\end{array}$ & $\begin{array}{l}3 / 8(37 \%) \\
(\mathrm{p}=0.131)\end{array}$ & $\begin{array}{l}7 / 14(50 \%) \\
(\mathrm{p}=0.134)\end{array}$ \\
\hline Adjuvant radiotherapy $(\mathrm{n}=10)$ & $\begin{array}{l}5 / 10(50 \%) \\
(p=0.285)\end{array}$ & $\begin{array}{l}5 / 7(71 \%) \\
(\mathrm{p}=0.482)\end{array}$ & $\begin{array}{l}2 / 5(40 \%) \\
(p=0.377)\end{array}$ & $\begin{array}{l}5 / 10(50 \%) \\
(\mathrm{p}=0.285)\end{array}$ \\
\hline $\begin{array}{l}\text { Metastasis during primary } \\
\text { diagnosis }(n=15)\end{array}$ & $\begin{array}{l}5 / 15(33 \%) \\
(p=0.586)\end{array}$ & $\begin{array}{l}11 / 13(85 \%) \\
(p=0.482)\end{array}$ & $\begin{array}{l}6 / 10(60 \%) \\
(\mathrm{p}=0.696)\end{array}$ & $\begin{array}{l}5 / 15(33 \%) \\
(p=0.586)\end{array}$ \\
\hline Vital tumor metastasis $(\mathrm{n}=18)$ & $\begin{array}{l}9 / 18(50 \%) \\
(p=0.052)\end{array}$ & $\begin{array}{l}11 / 14(78 \%) \\
(p=0.807)\end{array}$ & $\begin{array}{l}4 / 10(40 \%) \\
(p=0.091)\end{array}$ & $\begin{array}{l}8 / 18(44 \%) \\
(p=0.224)\end{array}$ \\
\hline
\end{tabular}

EFS: Event free survival

adjunct to assume the prognosis in pediatric pulmonary metastasectomies.

In our study, vital tumor tissue at metastatic nodules was identified in 18 patients at pathological examination (66\%). Six patients had necrotising tumor histopathology and did not require additional therapy. Moreover, benign pathologies like atelectatic lung tissue or non-specific calcified nodules were identified in three patients at pathological examination after surgical excision. Vital tumor metastasis was determined in all of the nodules which were enlarged after initial treatment. However, expected pathology could be different according to the behavior of nodules. Benign pathologies or necrotising tumor tissue were detected in five of 15 patients with new rising nodules $(33 \%)$. Therefore, all of the patients with new rising nodules should not be accepted as metastasis with only radiological studies. Pulmonary metastasectomy achieves certain pathological diagnosis in these patients.
In the follow-up, all of the patients with enlarging pulmonary metastatic nodules died in the postoperative period which were independent from the primary type of the tumor. Surgical excision only had positive effect on lengthening the life span but no effect on overall survival rate. After these results, we thought that pulmonary metastasectomy in patients with enlarging nodules under chemotherapy should be investigated more carefully for surgical interventions.

From the procedure aspect, thoracoscopic metastasectomy should be preferred in peripherallly localized nodules which could be visible during procedure. ${ }^{15}$ Palpation is usually advised in pulmonary nodules to exclude undetected nodules on CT scan. ${ }^{16-}$ 17 However, there are some studies which reported that non- palpable nodules do not affect survival due to their small size. ${ }^{18,19}$ In recent years, detailed CT scans could demostrate nodules with very small sizes. ${ }^{20}$ 
Therefore, a recent detailed CT scan should be obtained before surgery. On the other hand, thoracoscopic approach provides convenient for secondary pulmonary nodules requiring surgical intervention. ${ }^{21}$ The indications for thoracotomy should be included as non-visible or vast number of nodules which can not be resected thoracoscopically. Nodulectomy, wedge resection or segmentectomy could be preferred for nodule resection. ${ }^{22,23}$ Also, lobectomy should be performed in non-palpable and large nodules which are placed deeper in lung parenchyma and close to hilar structures. Surgical approach should be individualized according to the preoperative imaging studies.

Radiological nodule behavior (RNB) such as stable, new rising or enlarging nodules should be used in the surgical management strategies of pediatric pulmonary metastasectomies.

Stable nodules: None of the patients had vital tumor tissue at histopathological examination regardless of primary tumor types. Stabile nodules should be observed by close follow-up with serial CT scans without surgery.

Enlarging nodules: All of the patients with enlarging nodules recurred and died after surgery including osteosarcoma or Ewing's sarcoma. Nodule progression under chemotherapy is a poor prognostic criteria for overall survival. In our patients, surgery had a limited effect on lengthening the life span.

New rising nodules: One third of the nodules had benign pathologies in our study group. Patients with new rising nodules should not be accepted as pulmonary metastasis promptly. Surgical excision must be performed to avoid unnecessary chemotherapy in suspected nodules.

\section{Acknowledgement}

The statistical analysis was performed by Professor Mehmet N Orman (Ege University Faculty of Medicine, Department of Biostatistics; mehmet.orman@ege.edu.tr).

\section{REFERENCES}

1. Warwick R, Page R. Resection of pulmonary metastases from colorectal carcinoma. Eur J Surg Oncol 2007; 33: 59-63.

2. Younes RN, Gross JL, Taira AM, Martins AA, Neves GS. Surgical resection of lung metastases: results from 529 patients. Clinics (Sao Paulo) 2009; 64: 535-541.
3. Abel RM, Brown J, Moreland B, Parikh D. Pulmonary metastasectomy for pediatric solid tumors. Pediatr Surg Int 2004; 20: 630-632.

4. Acer T, Karnak I, Ciftçi AO, Akçören Z, Tanyel FC, Senocak ME. The prognostic factors in children undergoing pulmonary metastatectomy. Turk J Pediatr 2012; 54: 45-51.

5. Tronc F, Conter C, Marec-Berard P, et al. Prognostic factors and long-term results of pulmonary metastasectomy for pediatric histologies. Eur J Cardiothorac Surg 2008; 34: $1240-1246$.

6. Häcker FM, von Schweinitz D, Gambazzi F. The relevance of surgical therapy for bilateral and/or multiple pulmonary metastases in children. Eur J Pediatr Surg 2007; 17: 84-89.

7. Erginel B, Soysal FG, Keskin E, Kebudi R, Celik A, Salman T. Pulmonary metastasectomy in pediatric patients. World J Surg Oncol 2016; 14: 27.

8. Brader P, Abramson SJ, Price AP, et al. Do characteristics of pulmonary nodules on computed tomography in children with known osteosarcoma help distinguish whether the nodules are malignant or benign? J Pediatr Surg 2011; 46: 729-735.

9. Mizuno T, Taniguchi T, Ishikawa Y, et al. Pulmonary metastasectomy for osteogenic and soft tissue sarcoma: Who really benefits from surgical treatment? Eur J Cardiothorac Surg 2013; 43: 795-799.

10. Briccoli A, Rocca M, Salone M, et al. Resection of recurrent pulmonary metastases in patients with osteosarcoma. Cancer 2005; 104: 1721-1725.

11. Hartin MT, Blakely ML. Management of osteosarcoma pulmonary metastases. Semin Pediatr Surg 2006; 15: 25-29.

12. Meyers RL, Katzenstein HM, Krailo M, McGahren ED 3rd, Malogolowkin MH. Surgical resection of pulmonary metastatic lesions in children with hepatoblastoma. J Pediatr Surg 2007; 42: 2050-2056.

13. Stanelle EJ, Christison-Lagay ER, Wolden SL, Meyers PA, La Quaglia MP. Pulmonary metastasectomy in pediatric/adolescent patients with synovial sarcoma: An institutional review. J Pediatr Surg 2013; 48: 757-763.

14. Letourneau PA, Shackett B, Xiao L, et al. Resection of pulmonary metastases in pediatric patients with Ewing sarcoma improves survival. J Pediatr Surg 2011; 46, 332-325.

15. Gow KW, Saad DF, Koontz C, Wulkan ML. Minimally invasive thoracoscopic ultrasound for localization of pulmonary nodules in children. J Pediatr Surg 2008; 43: 2315-2322.

16. Kaytona ML, Huvosb AG, Casher J, et al. Computed tomographic scan of the chest underestimates the number of metastatic lesions in osteosarcoma. J Pediatr Surg 2006; 41: 200-206.

17. Parsons AM, Detterbeck FC, Parker LA. Accuracy of helical CT in the detection of pulmonary metastases: is intraoperative palpation still necessary? Ann Thorac Surg 2004; 78: 1910-1916. 
18. Macherey S, Doerr F, Heldwein M, Hekmat K. Is manual palpation of the lung necessary in patients undergoing pulmonary metastasectomy? Interact Cardiovasc Thorac Surg 2016; 22: 351-359.

19. Cerfolio RJ, Bryant AS, McCarty TP, Minnich DJ. A prospective study to determine the incidence of nonimaged malignant pulmonary nodules in patients who undergo metastasectomy by thoracotomy with lung palpation. Ann Thorac Surg 2011; 9: 1696-1700.

20. Pfannschmidt J, Bischoff M, Muley T, et al. Diagnosis of pulmonary metastases with helical CT: The effect of imaging techniques. Thorac Cardiovasc Surg 2008; 56: $471-475$
21. Chao YK, Chang HC, Wu YC, et al. Management of lung metastases from colorectal cancer: Video-assisted thoracoscopic surgery versus thoracotomy--a casematched study. Thorac Cardiovasc Surg 2012; 60: 398-404.

22. Su WT, Chewning J, Abramson S, et al. Surgical management and outcome of osteosarcoma patients with unilateral pulmonary metastases. J Pediatr Surg 2004; 39: 418-423.

23. Fuchs J, Seitz G, Ellerkamp V, et al. Analysis of sternotomy as treatment option for the resection of bilateral pulmonary metastases in pediatric solid tumors. Surg Oncol 2008; 17: 323-330. 